\title{
Acute Epidural and Subdural Hematomas After Head Injury: Clinical Distinguishing Features
}

\author{
Bartłomiej Kulesza $^{1}$ (D) $\cdot$ Marek Mazurek ${ }^{1} \cdot$ tukasz Rams $^{2} \cdot$ Adam Nogalski $^{3}$ (D)
}

Received: 29 June 2019 / Accepted: 30 April 2020 / Published online: 20 May 2020

(C) The Author(s) 2020

\begin{abstract}
Head injury remains the most common cause of death and disability in young people. The most frequent consequences of traumatic brain injury (TBI) are extra-axial hemorrhage, i.e., an acute subdural hematoma (SDH) and epidural hematoma $(\mathrm{EDH})$, which usually require a surgical treatment. The aim of the study is to present the distinguished clinical features associated with patients being surgically treated for post-traumatic EDH and SDH. The study included a group of 128 patients with isolated craniocerebral injuries. All the patients were operated. The following factors from the groups were analyzed: demographic data, physiological factors, laboratory factors, computed tomography scan characteristics, the time between trauma and surgery, and the in-hospital mortality. Using statistical analysis, we compared the studied factors in patients operated on due to EDH and SDH. Patients with SDH were older than patients with EDH. Most often, extra-axial hematomas affected men. Patients with SDH were more severe condition than patients with EDH on admission. Abnormal systolic blood pressure was the most common manifestation of dysautonomia in both groups. In the SDH group, we observed hypotension more often than hypertension. Hyperglycemia was one of the most common anomalies in laboratory factors in both groups. Hypotension and hyperglycemia were that factors significantly associated with outcome after head injuries. SDH caused greater midline shift and often pressed in basal cisterns. Patients with SDH died more often than patients with EDH.
\end{abstract}

Keywords Traumatic brain injury $\cdot$ Extra-axial hematoma $\cdot$ Epidural hematoma $\cdot$ Subdural hematoma

Bartłomiej Kulesza

kuleszabartek88@gmail.com

Marek Mazurek

Marekmazurek@hotmail.com

Łukasz Rams

rams.lukasz@gmail.com

Adam Nogalski

chirurgiaurazowalublin@tlen.pl

1 Chair and Department of Neurosurgery and Paediatric Neurosurgery, Medical University in Lublin. Independent Public Clinical Hospital No. 4 in Lublin, Jaczewskiego 8, 20-954 Lublin, Poland

2 Department of Neurosurgery, AK Altona Hamburg, Paul-Ehrlich-Straße 1, 22763 Hamburg, Germany

3 Chair and Department of Trauma Surgery and Emergency Medicine, Medical University in Lublin, Independent Public Clinical Hospital No. 1 in Lublin Poland, Stanisława Staszica 16, 20-400 Lublin, Poland

\section{Introduction}

Head injury is one of the most important causes of death and disability among people, especially young adults. It is estimated that about sixty-nine million people around the world experience traumatic brain injury (TBI) every year. The effect of TBI may be extra-axial hemorrhage, i.e., an acute subdural and epidural hematoma, which usually requires immediate treatment. Most often, intracranial hematomas are a consequence of severe head injuries $[1,2]$. Acute EDHs are identified on head CT as a hyperdense collection in the epidural space, which is located between the inner table of the skull and the dura mater. Subdural hematomas (SDH) are much more common than EDHs. Acute subdural hematomas are identified on head CT as hyperdense hemorrhage into the subdural space, which is interposed between the arachnoid and pia mater [3, 4]. The aim of the study is to present the distinguished clinical features associated with patients being surgically treated for post-traumatic EDH and SDH, among patients who presented to the single neurosurgical center. 


\section{Patients and Methods}

A group of 128 patients with isolated head injury was included in the study. Twenty-eight patients were operated on due to epidural hematoma (EDH group), and a group of 100 patients were operated on due to acute subdural hematoma (SDH group). All the patients were operated and treated after surgery in the Department of Neurosurgery from 1 October 2014 to 31 August 2017. During this period of time, 146 patients were treated surgically for EDH and SDH, whereas 18 patients were excluded from the study. Exclusion criteria include the lack of complete medical documentation, incomplete laboratory tests, and the lack of description of the computed tomography $(\mathrm{CT})$.

All of the factors were collected retrospectively on the admission of patients in the Emergency Department. The following factors from the groups were analyzed: demographic data, physiological factors, laboratory factors, computed tomography scan characteristics, and the time between trauma and surgery. The records were examined for demographic data, such as gender and age. Physiological factors included initial GCS, pupil reaction to light (normal, a non-reactive one, or both), saturation, systolic blood pressure (SBP), heart rate (HR), and respiratory rate (RR) (normal or abnormal value). Hypotension was determined when the SBP value was $\leq$ $89 \mathrm{mmHg}$ while the SBP $\geq 141 \mathrm{mmHg}$ as hypertension. Laboratory factors included the number of white blood cells (WBC), hemoglobin (HGB), number of platelets (PLT), glycaemia, sodium concentration, coagulopathy, and alcohol levels. Laboratory factors were analyzed on the basis of two groups: normal values and outstanding ones. Additionally, coagulopathy and the state after alcohol intoxication were examined. Coagulopathy was defined as INR $>1.2$ or PT $>$ $12.7 \mathrm{~s}$. For the state of intoxication, the alcohol concentration was higher than $0.6 \%$. The study contained the presence of characteristics from the $\mathrm{CT}$, such as the present skull fracture, subarachnoid hemorrhage (SAH), intraventricular hemorrhage (IVH), cerebral contusion, maximum thickness of the hematoma, midline shift (MLS), and obliteration basal cistern. The last factor was the time between the injury and the surgery. We investigated the in-hospital mortality of patients at the time of discharge (Table 1).

\section{Statistical Analysis}

To compare two independent groups, the Mann-Whitney $U$ test was used. The Kruskal-Wallis test was used to compare the age of the groups, and Spearman's R correlations were used to examine the relationship between the variables. The $\mathrm{Chi}^{2}$ homogeneity test was performed to detect differences in unrelated qualitative characteristics between groups. A significance level of $p<0.05$ was assumed as statistically significant differences. The statistical research were based on the STATISTICA 13.0 computer software (StatSoft, Poland).

\section{Results}

\section{Demographic Data}

The mean age of patients in SDH group was $57.86 \pm$ 18.26 years, and it was statistically significantly higher than the mean age of patients with epidural hematoma- $38.82 \pm$ 13.37 years $(p=0.00001)$ (Table 2$)$. In both groups, men were hospitalized more often (Table 1).

\section{Physiological Factors}

The patients with SDH (median 6) had statistically significantly lower scores in the GCS (Glasgow Coma Scale) than patients in EDH group (median 11.5) $(p=0.0006)$ (Table 2), (Fig. 1).

In the SDH group, more $(60 \%)$ patients had 8 or less points in GCS than in the EDH group (32.1\%), ( $p=0.004)$ (Table 1).

The systolic blood pressure was more frequently abnormal in the SDH group (57\%) than in the EDH group (35.7\%), $(p=$ $0.05)$. In the SDH group, hypotension was found more often (33\%) than hypertension (24\%). In the EDH group, hypertension was more common than hypotension ( $21.4 \%$ vs. $14.3 \%)$. In the SDH group, an abnormal value of breaths per minute (42\%) was more frequent compared with the other group (21.4\%), $(p=0.05)$. Both differences were close to statistical significance. Saturation $\leq 96 \%$ was statistically significantly more frequent in the SDH group than $\mathrm{EDH}$ (53\% vs. 17.9\%), $(p=0.001)$. In the group with subdural hematomas, the lack of reactivity of both pupils was more frequent $(41 \%)$ in comparison with patients with $\mathrm{EDH}(25 \%),(p=0.10)$. Statistical analysis did not show significant differences between groups in the assessment of heart rate per minute (HR) $(p=0.40)$ (Table 1).

\section{Laboratory Factors}

Leukocytosis $(64.3 \%)$ and anemia (25\%) were slightly more frequent in EDH group than in the SDH group (respectively $49 \%$ and $21 \%$ ) ( $p=0.33$ and $p=0.65)$. In SDH group, thrombocytopenia (28\%), hyperglycemia (78\%), and coagulopathy $(31 \%)$ occurred slightly more frequently than in EDH group, respectively $(17.9 \%, 75 \%$, and $28.6 \%),(p=0.54,0.74$, and 0.81$)$. In the case of sodium concentration, statistical analysis did not show significant differences (Table 2). 


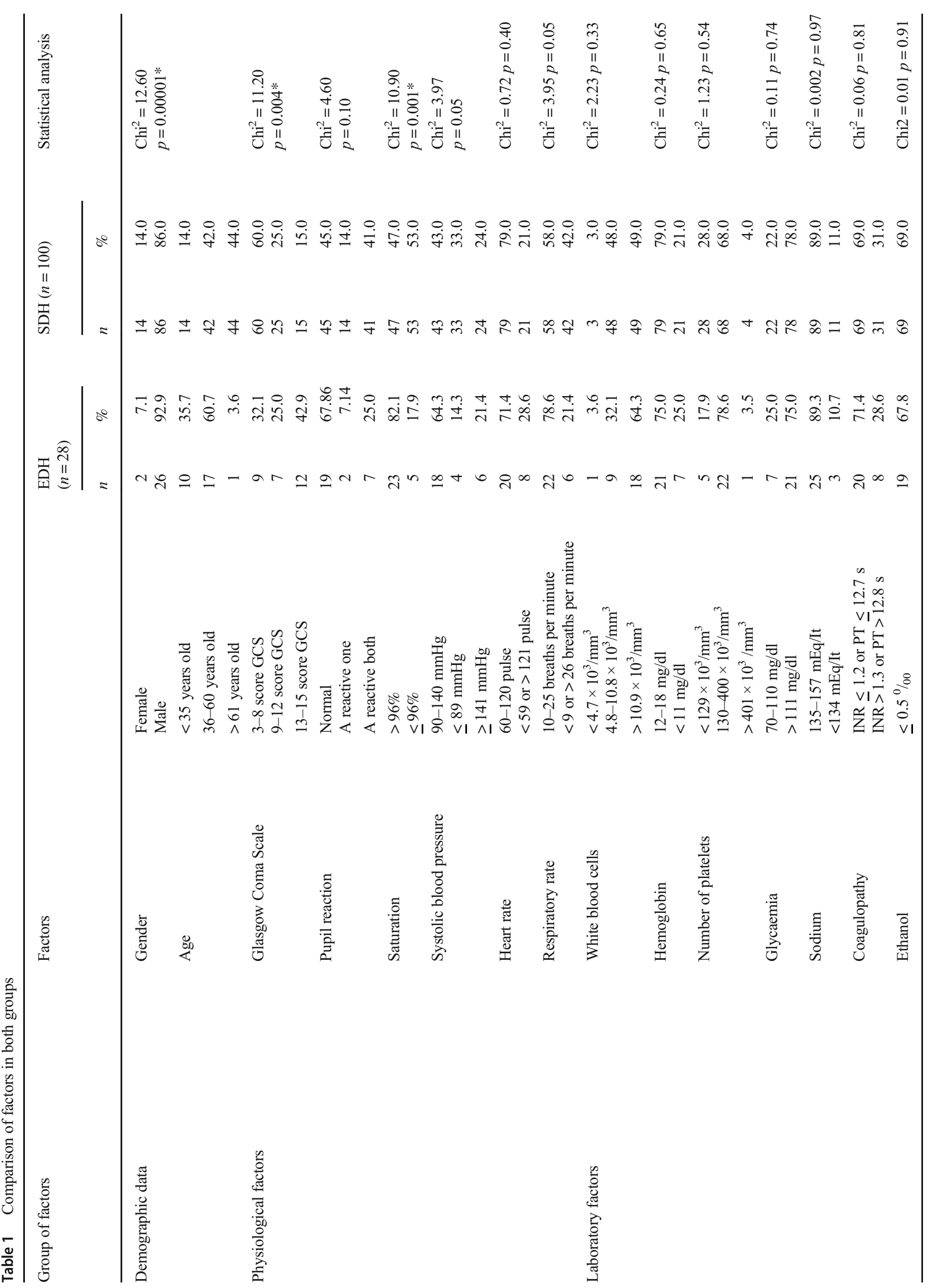




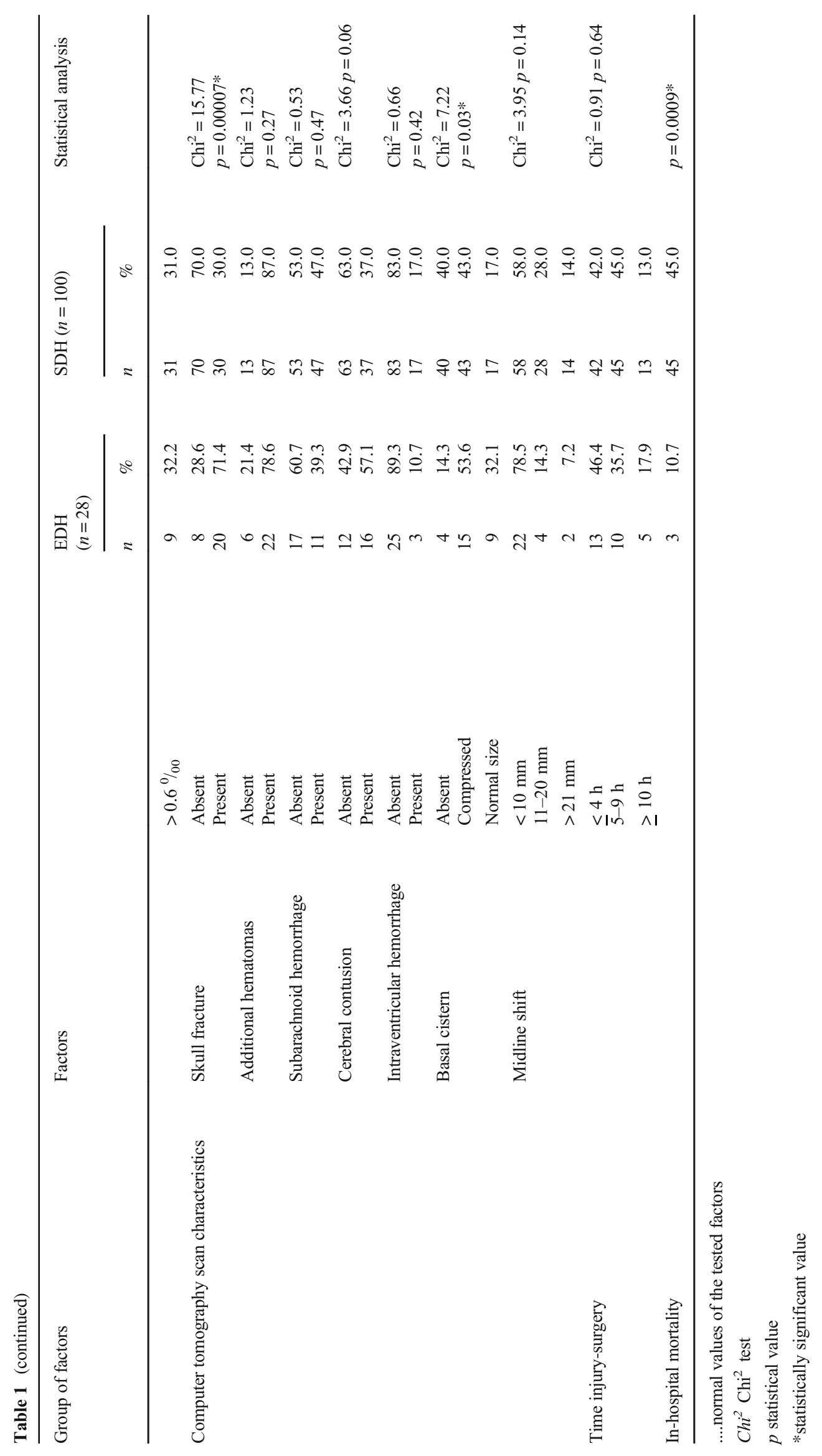




\section{Computer Tomography Scan Characteristics}

Skull fracture was associated more often with patients with EDH (71.4\%) than SDH (30\%), ( $p=0.00007)$. Basal cisterns were compressed and absent more often in the SDH group $(83 \%)$ than in EDH group (67.9\%), $(p=0.03)$. Cerebral contusion was more often found in the EDH group (57.1\%) than in SDH group $(37 \%),(p=0.06)$. There were no significant differences between the groups when it comes to assessment concerning presence of additional hematoma, SAH and IVH. The thickness of the hematoma was significantly higher in EDH group (median $26.5 \mathrm{~mm}$ ) than in SDH group (median $17 \mathrm{~mm}),(p=0.00004)$. Midline shift was greater in the SDH group (median $10 \mathrm{~mm}$ ) than in EDH group (median $9 \mathrm{~mm}$ ), $(p=0.05)$ (Table 1), (Fig. 2). The thickness of hematoma was most often 11-20 $\mathrm{mm}(60 \%)$ in SDH group and $\leq 30 \mathrm{~mm}$ (60.7\%) in EDH group. In the group with SDH, the midline shift of over $20 \mathrm{~mm}$ was slightly greater (14\%) than in the group with $\mathrm{EDH}(7.1 \%),(p=0.14)$ (Table 1).

\section{Time Injury-Surgery}

Time between trauma and surgery did not differ significantly between groups $(p=0.91)$ (Table 2), (Fig. 1). In the EDH group, the time to surgery over $10 \mathrm{~h}(17.9 \%)$ was more frequent than in the SDH group $(13 \%),(p=0.64)$ (Table 1).

\section{In-Hospital Mortality}

Within patients in SDH group, death during hospitalization was more frequent $(45 \%)$ compared with the EDH group (10.7\%), $(p=0.0009)$. Median time to hospital mortality was slightly longer in the EDH group (4 days) in comparison with SDH group (3 days) $(p=0.71)$ (Table 2, Fig. 1).

\section{Discussion}

\section{Demographic Date}

Epidural hematomas usually affect young people, less often children before the age of 2 and people over 60 years of age [4]. Only $2-14 \%$ of patients are above the age of 60 ; peak incidence of EDH placing between the second to fourth decade and the average age of patients with EDH is between 20 and 45 years of age $[5,6]$. In our EDH group, mean age was 38.82 , and only one patient (3.6\%) was above 60 years old. Subdural hematomas are found at any age, with some preference for older people $[4,7]$. In our study in SDH group, mean age was 57.86 years. Patients with acute subdural hematomas were statistically significantly older than patients with EDH. Literature shows that average age for patients with SDH is between 45 and 63 years old [8, 9]. Age is one of the most important factors affecting in-hospital mortality and outcome in TBI [10].

Table 2 Mean, median, and standard deviation of the studied factors in both groups

\begin{tabular}{|c|c|c|c|c|c|c|c|c|}
\hline \multirow[t]{2}{*}{ Factors } & \multicolumn{3}{|c|}{ Epidural hematomas } & \multicolumn{3}{|c|}{ Subdural hematomas } & \multicolumn{2}{|c|}{ Statistical analysis } \\
\hline & Mean & Median & Standard deviation & Mean & Median & Standard deviation & $Z$ & $P$ \\
\hline Age & 38.8 & 37.0 & 13.4 & 57.9 & 59.0 & 18.3 & 4.82 & $0.00001 *$ \\
\hline GCS score & 10.6 & 11.5 & 4.4 & 7.4 & 6.0 & 4.0 & 3.44 & $0.0006^{*}$ \\
\hline WBC & 12.4 & 12.2 & 4.6 & 11.9 & 10.7 & 5.3 & 0.71 & 0.48 \\
\hline PLT & 211.1 & 197.0 & 90.4 & 199.7 & 179.0 & 128.0 & 1.22 & 0.22 \\
\hline HGB & 13.2 & 13.8 & 1.9 & 13.4 & 13.7 & 1.9 & -0.32 & 0.75 \\
\hline Sodium & 140.9 & 140.0 & 5.2 & 139.6 & 140.0 & 5.3 & 0.93 & 0.35 \\
\hline Glycemia & 143.1 & 133.0 & 37.6 & 159,21 & 139.5 & 59.4 & 0.62 & 0.54 \\
\hline INR & 1.1 & 1.1 & 0.1 & 1.4 & 1.1 & 1.3 & -0.59 & 0.56 \\
\hline $\mathrm{PT}$ & 11.9 & 11.8 & 1.2 & 13.6 & 11.8 & 10.8 & 0.13 & 0.89 \\
\hline Alcohol & 2.1 & 2.5 & 0.8 & 2.6 & 2.6 & 1.1 & 0.87 & 0.39 \\
\hline Thickness of hematomas & 27.3 & 26.5 & 10.6 & 18.4 & 17.0 & 8.4 & 4.12 & $0.00004 *$ \\
\hline MLS & 8.5 & 9.0 & 5.4 & 11.2 & 10.0 & 7.1 & -1.93 & 0.05 \\
\hline Time injury-surgery & 15.7 & 5.0 & 31.7 & 9.9 & 5.0 & 14.0 & 0.12 & 0.91 \\
\hline Time to hospital mortality & 11.4 & 4.0 & 16.2 & 5.9 & 3.0 & 8.0 & -0.38 & 0.71 \\
\hline
\end{tabular}

$Z$ Mann-Whitney $U$ test

$p$ statistical value

*statistically significant value 


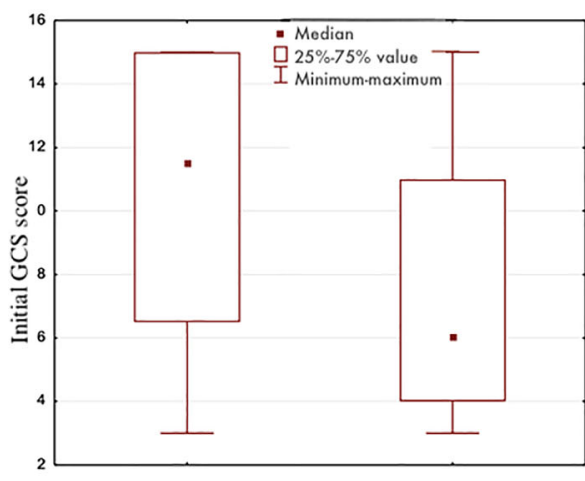

Epidural hematomas Subdural hematomas

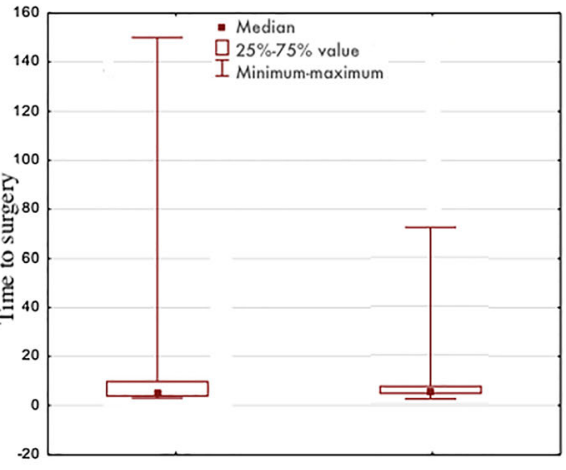

Epidural hematomas Subdural hematomas

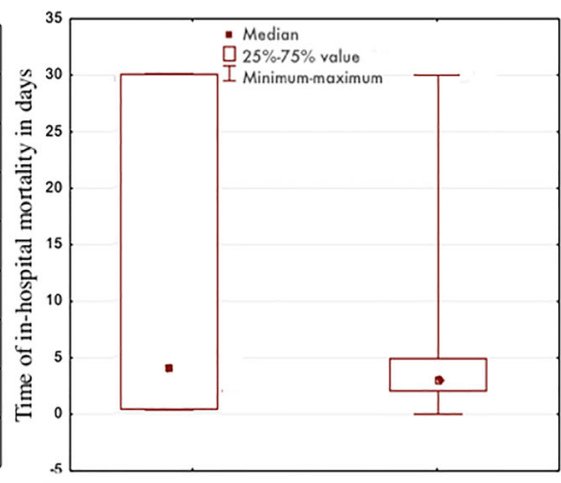

Epidural hematomas Subdural hematomas

Fig. 1 Initial GCS score, time to surgery, and time of in-hospital mortality in both groups

TBI is much more common in men than women, because men behave more risky than women, especially in younger age where men are more often exposed to violence and communication injuries $[2,4]$. The male dominance among the victims of EDH is recognized with only $6.5-21 \%$ of cases in different studies being female [5,6]. In our study, $7.1 \%$ of $\mathrm{EDH}$ group were women. In SDH group, women represent $14 \%$ of all patients. In other study, women constitute from 20 to $40 \%$ among patients with $\mathrm{SDH}[8,9,11]$.

\section{Physiological Factors}

In our study, $67.9 \%$ patients had mild to moderate TBI, and $32.1 \%$ patients were comatose (3-8 GCS) on admission in EDH group. Literatures show that $20-30 \%$ patients with EDH suffered from severe TBI (3-8 GCS) $[5,12]$. In SDH group, $60 \%$ of patients suffered from severe TBI. In literatures, $45-60 \%$ of patients scored 8 and less points in GCS $[8,9,13]$. SDH patients had significantly less points in the GCS than patients in EDH group, $(p=0.0006)$. Age followed by GCS score and pupil response are the strongest independent prognostic factors in TBI. In addition, age similar to GCS creates a linear function, the lower score in GCS associated with the worse outcome [10,14].

In our study, pupillary abnormalities were present in $32.1 \%$ cases in EDH group. Most studies describe the pupillary abnormalities between 20 and $35 \%$ among EDH patients $[6,15]$. In our study, pupillary abnormalities were present in 55\% in SDH group. In other authors, pupillary abnormalities were described between 40 and $60 \%$ [8, 13, 16, 17]. Bilateral dilated pupils are more frequent than unilateral dilated pupil in both groups, and the result was similar to those of other series [16].

TBI causes dysautonomia manifested by episodes of fluctuations in blood pressure, pulse rate, respiratory rate, temperature, muscle tone, decorticate or decerebrate posturing, and profuse sweating [1]. Hypoxia causes rapid brain destruction and together with hypotension are considered as secondary insults, which are associated with poorer outcome and higher mortality $[14,18]$. In present study, abnormal value of systolic

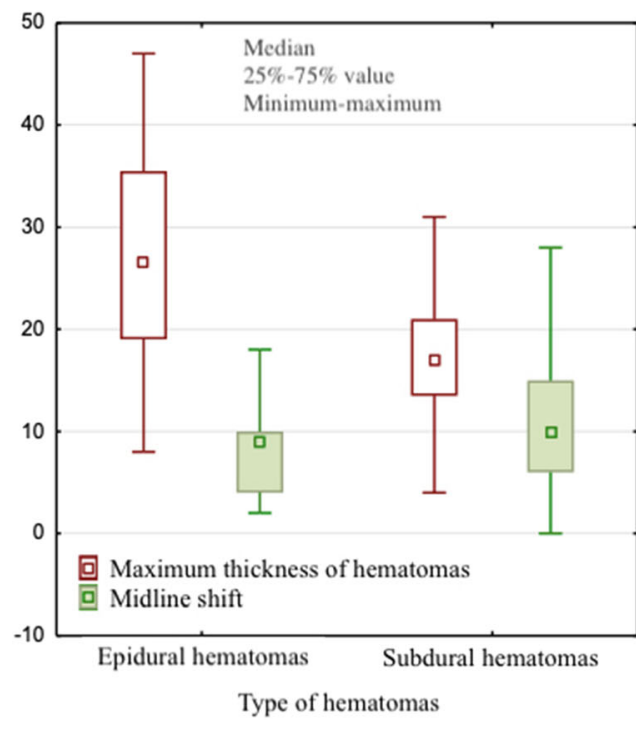

Maximum thickness of hematoma in patients with epidural hematomas

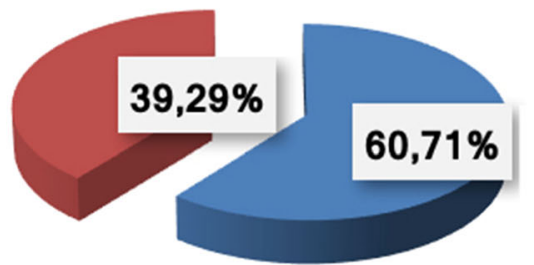

$\square<30 \mathrm{~mm} \quad>30 \mathrm{~mm}$
Maximum thickness of hematoma in patients with subdural hematomas

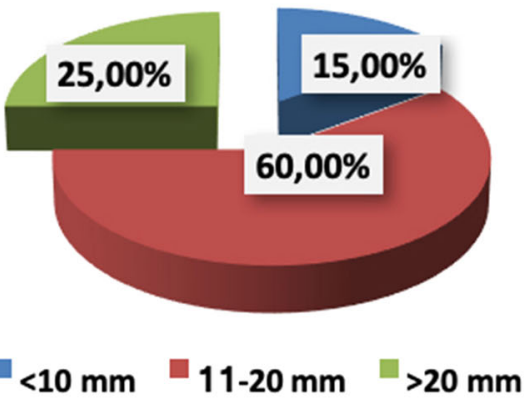

Fig. 2 Maximum thickness of hematomas and midline shift in both groups 
blood pressure (35.7\%) was the most common manifestation of dysautonomia in EDH group. Yurt et al. show that bradycardia and arterial hypertension were noticed in $23 \%$ of patients [15]. In case of SDH group, we found hyper and hypotension among $57 \%$ of patients, with as much as $33 \%$ of patients suffering from hypotension. Two studies show that hypotension was in $8.3 \%$ and $26.7 \%$ of all patients $[19,20]$. In this study, we found saturation equal and below $96 \%$ in 53\% of patients in SDH group. In Kalayci study, $61.8 \%$ patients had saturation $\leq 96 \%$ [11]. Only saturation was significantly more frequent in the SDH group than EDH, $(p=0.001)$. Hypoxia and hypotension were common in the SDH group in which the patients' condition in GCS was significantly more severe than in the EDH group.

\section{Laboratory Factor}

Head injury is associated with increased blood levels of catecholamines and cortisol. Catecholamines release neutrophil stores, and corticosteroids cause a decrease in the egress of neutrophils from the circulation. The acute-phase response is also characterized by a leukocytosis on admission [19]. In patients with subdural hematoma, a mean number of leukocytes were found at $18.2 \times 10^{3} / \mu \mathrm{l}$. In patients with epidural hematoma, a mean of leukocytes was $16.5 \times 10^{3} / \mu$ l on admission [21]. In present study, mean number of WBC in SDH and EDH group were respectively 11.9 and $12.4 \times 10^{3} / \mu 1$. Additionally, abnormal number of WBC was found in $52 \%$ patients in SDH group in Atanasov study in 55.3\% [16].

Hyperglycemia is one of the most common secondary damage in patients after severe TBI, and it is associated with a poorer outcome [14, 22]. Atanasov at al. described hyperglycemia in $85.9 \%$ among patients with SDH [16]. We found hyperglycemia in 75\% patients in EDH group and in 78\%SDH group. Mean glycaemia values were 159.2 and $143.1 \mathrm{mg} / \mathrm{dl}$, respectively, in EDH and SDH group. Early monitoring of blood glucose in the range of $80-110 \mathrm{mg} / \mathrm{dl}$ can protect against nerve ischemia damage, reduce disability, and improve patient prognosis [23].

TBI was associated with serum sodium disorders, especially with hypernatremia. However both hypo- and hypernatremia are associated with a poorer outcome [10]. The incidence of sodium disturbances was found in about half of patients with TBI. In case of SDH, sodium disturbance was found in $31.3 \%$ of patients. In case of EDH, $22.5 \%$ patients had sodium disturbance [24]. Atanasov et al. described hyponatremia in $16.5 \%$ among patients with SDH [16]. In our study, no patients had hypernatremia, although there was $11 \%$ patients with hyponatremia in SDH group and $10.7 \%$ in EDH group.

We found abnormal number of PLT in 32\% patients with $\mathrm{SDH}$; Atanasov et al. described that incidence in $17.6 \%$ patients [16]. In present study, anemia was noted in $21.9 \%$ cases in both groups. Anemia and thrombocytopenia on admission are associated with poorer outcomes [10,14]. Mayr showed incidents of coagulopathy among patients with EDH in 25\% [25]; we found coagulopathy in $28.6 \%$ in EDH group and $31 \%$ in SDH group. Incidents of coagulopathy among patients with TBI were in $11.9 \%$ cases [20]. The risk of patient death after TBI with coagulopathy is about 10 times higher than patients without coagulopathy [26].

Alcohol consumption increases the risk of all types of trauma. Up to $50 \%$ of all patients suffering TBI are intoxicated at the time of injury [20]. In our study, $31.3 \%$ of all patients were alcohol intoxicated in both group.

\section{Compute Tomography Scan Characteristic}

In our study, $71.4 \%$ patient with epidural hematomas had a skull fractures. Most studies describe the incidence between 70 and $85 \%[6,14]$. Skull fracture was significantly often associated with patients with EDH.

The mean thickness of EDH was $27.3 \mathrm{~mm}$ in present study. In other study, mean thickness was $22.4 \mathrm{~mm}$ and $24.3 \mathrm{~mm} \mathrm{[5}$, 12]. The MLS evaluation showed that there was a shift of less and equal $10 \mathrm{~mm}$ in $78.6 \%, 11-20 \mathrm{~mm}$ in $14.3 \%$, and greater than $21 \mathrm{~mm}$ in $7.1 \%$. In Zhang et al.'s study, MLS was < $10 \mathrm{~mm}$ in $77.3 \%$ and $>10 \mathrm{~mm}$ in $22.7 \%$ [12]. CT scan results showed that basal cisterns were pressed in $67.9 \%$ cases; $\mathrm{SAH}$, $39.9 \%$; additional hematoma, $78.6 \%$; IVH, $10.7 \%$; and contusion presented in $57.1 \%$ cases. Other study described additional hematoma in $40.9 \%$, SAH in $21.6 \%$ or $47.2 \%$, IVH in $12 \%$, and contusion in $40.3 \%$ or $46.9 \%[10,12]$.

In SDH group, the mean thickness was 18.4 and was significantly smaller than in EDH group. Walcott et al. found mean thickness-14.4 $\mathrm{mm}$ [27]. MLS less than $10 \mathrm{~mm}$ was in $58 \%$ cases in present study. Most authors confirm that the most MLS was shift up to $10 \mathrm{~mm}[11,13]$. CT scan results showed that basal cisterns were pressed in 87\%; SAH presented in 47\%; additional hematoma, $87 \%$; IVH, $17 \%$; and contusion in $37 \%$ cases. Other study described basal cistern compress in $70 \%$, SAH between 33 and $85 \%$, IVH in $10.3 \%$, and contusion between 20 and $65 \%$. The most study described SAH and contusion about in $50 \%[11,13,27]$.

SDH cause a greater mass effect than EDH in the form of greater midline shift and compressed basal cisterns [4, 7]. Present study confirm that association, because basal cistern often was pressed and midline shift was greater in the SDH than in EDH group $(p \leq 0.05)$. A lot of authors studying patients with hematomas found a higher mortality associated with a greater MLS and the thickness of hematoma. Additionally, presence of SAH, IVH, and contusion testifies to greater severity of injury and associated with higher mortality $[10,26,28]$. 


\section{Time Injury-Surgery}

Time injury-surgery is an important factor, and minimizing this time can significantly reduce in-hospital mortality [29]. The mean time from injury to surgery was $15.7 \mathrm{~h}$ in present study in EDH group. In study from China, the mean time between trauma and surgical evacuation of EDH was $10.9 \mathrm{~h}$ [12] or $78 \mathrm{~h}$ in other study [5]. The mean time between injury and surgery was $9.9 \mathrm{~h}$ in SDH group, and 58\% patients were operated over $4 \mathrm{~h}$ after the injury. The mean time injurysurgery was 5.4 and $14.2 \mathrm{~h}$ in other study [27, 30], and $73.5 \%$ and $80 \%$ of patients were operated over $4 \mathrm{~h}$ after the injury $[16,17]$. However, time between trauma and surgery did not differ significantly.

\section{In-Hospital Mortality}

Our in-hospital mortality among patients with EDH was $10.7 \%$. Mortality rate in case of EDH was from 2.6 to $15.5 \%$, the most study described mortality rate about $10 \%$ $[3,5,6]$. In SDH group, our study showed mortality rate of $45 \%$. Mortality in the subdural hematoma varies from 22 to $75 \%$; most often the results oscillate about $40 \%[3,11,13$, 17]. In patients with $\mathrm{SDH}$, death during hospitalization was significantly frequent compared with the group with epidural hematoma $(p=0.0009)$.

\section{Conclusion}

Patients with SDH were nearly twice as old as patients with EDH. Most often, extra-axial hematomas affect men, especially the male dominance among the victims of EDH. Patients with SDH were more severe condition than patients with EDH on admission. Two times more patients with SDH suffered severe TBI (3-8 GCS) compared with EDH patients. The effects of dysautonomia were more often in patients with SDH than EDH. Hypo- and hypertension were the most common manifestations of dysautonomia in case of patients with extra-axial hematomas. Hypotension and hypoxia are often associated with a patient in severe condition with SDH. These factors worsen the patient's prognosis, so they should be treated as soon as possible. Hyperglycemia and leukocytosis were the most common anomalies in laboratory factors routinely recorded on admission. Hyperglycemia is another factor that is significantly associated with prognosis. Despite the fact that EDH had a greater hematoma thickness, SDH caused greater midline shift and often pressed in basal cisterns. Patients with SDH died more than four times more often during hospitalization than patients with EDH.

\section{Compliance with Ethical Standards}

Conflict of Interest Bartłomiej Kulesza, Marek Mazurek, Łukasz Rams, and Adam Nogalski declare that they have no conflict of interest.

Consent Ethics Commission The study obtained the consent of the Bioethics Commission located at the Medical University of Lublin (Number of consent KE-0254/313/2016). This type of study does not require informed consent.

Open Access This article is licensed under a Creative Commons Attribution 4.0 International License, which permits use, sharing, adaptation, distribution and reproduction in any medium or format, as long as you give appropriate credit to the original author(s) and the source, provide a link to the Creative Commons licence, and indicate if changes were made. The images or other third party material in this article are included in the article's Creative Commons licence, unless indicated otherwise in a credit line to the material. If material is not included in the article's Creative Commons licence and your intended use is not permitted by statutory regulation or exceeds the permitted use, you will need to obtain permission directly from the copyright holder. To view a copy of this licence, visit http://creativecommons.org/licenses/by/4.0/.

\section{References}

1. Dewan MC, Rattani A, Gupta S, Baticulon RE, Hung YC, Punchak M, Agrawal A, Adeleye AO, Shrime MG, Rubiano AM, Rosenfeld JV, Park KB (2018) Estimating the global incidence of traumatic brain injury. J Neurosurg 130:1-18. https://doi.org/10.3171/2017. 10.JNS17352

2. Peeters W, Van den Brande R, Polinder S et al (2015) Epidemiology of traumatic brain injury in Europe. Acta Neurochir 157:1683-1696

3. Tallon JM, Ackroyd-Stolarz S, Karim SA et al (2008) The epidemiology of surgically treated acute subdural and epidural hematomas in patients with head injuries: a population-based study. Can J Surg 51:339-345

4. Greenberg MS (2016) Handbook of Neurosurgery, 8th edn. Thieme, New York, pp 892-898

5. Ndoumbe A, Ekeme MP, Jemea B et al (2016) Epidemiological analysis of surgically treated acute traumatic epidural hematoma. Open J Mod Neurosurg 6:89-97

6. Chowdhury Noman Khaled SM, Raihan MZ, Chowdhury FH et al (2008) Surgical management of traumatic extradural haematoma: experiences with 610 patients and prospective analysis. Indian $\mathrm{J}$ Neurotrauma 5(2):75-79

7. Osborn AG, Salzman KL, Hedlund GL (2017) Osborn's brain, 2 edn. Elsevier, Hardcover, pp 21-29

8. Li LM, Kolias AG, Guilfoyle MR, Timofeev I, Corteen EA, Pickard JD, Menon DK, Kirkpatrick PJ, Hutchinson PJ (2012) Outcome following evacuation of acute subdural haematomas: a comparison of craniotomy with decompressive craniectomy. Acta Neurochir 154:1555-1561

9. Kim KH (2009) Predictors for functional recovery and mortality of surgically treated traumatic acute subdural hematomas in 256 patients. J Korean Neurosurg Soc 45(3):143-150

10. Kulesza B, Litak J, Mazurek M, Nogalski A (2020) The initial factors affecting 6-month outcome of patients undergoing surgery for acute post-traumatic subdural and epidural hematoma. Folia Med (Plovdiv) 62(1):94-104. https://doi.org/10.3897/folmed.62. e47743 
11. Kalayci M, Aktunç E, Gül S et al (2013) Decompressive craniectomy for acute subdural haematoma: an overview of current prognostic factors and a discussion about some novel prognostic parameters. J Pak Med Assoc 63(1):38-49

12. Zhang S, Wang S, Wan X, Liu S, Shu K, Lei T (2017) Clinical evaluation of post-operative cerebral infarction in traumatic epidural haematoma. Brain Inj 31(2):215-220

13. Tian HL, Chen SW, Xu T et al (2008) Risk factors related to hospital mortality in patients with isolated traumatic acute subdural hematoma: analysis of 308 patients undergone surgery. Chin Med J 121:1080-1084

14. Kulesza B, Litak J, Grochowski C, Nogalski A, Rola R (2020) The initial factors with strong predictive value in relation to six-month outcome among patients operated due to extra-axial hematomas. Diagnostics 10(3):174. https://doi.org/10.3390/ diagnostics 10030174

15. Yurt I, Bezircioglu H, Ersahin Y et al (1996) Extradural haematoma: analysis of 190 cases. Turk Neurosurg 6:63-67

16. Atanasov VA, Popov RV (2016) Predictors for outcome after surgery for traumatic acute subdural hematoma. Rom Neurosurg 3(30):366-374

17. Karasu A, Civelek E, Aras Y et al (2010) Analyses of clinical prognostic factors in operated traumatic acute subdural hematomas. Ulusal travma ve acil cerrahi dergisi $=$ Turkish $\mathrm{J}$ Trauma Emerg Surg 16:233-236

18. Okonkwo DO, Shutter LA, Moore C, Temkin NR, Puccio AM, Madden CJ, Andaluz N, Chesnut RM, Bullock MR, Grant GA, McGregor J, Weaver M, Jallo J, LeRoux PD, Moberg D, Barber J, Lazaridis C, Diaz-Arrastia RR (2017) Brain oxygen optimization in severe traumatic brain injury phase-II: a phase II randomized trial. Crit Care Med 45(11):1907-1914

19. Rovlias A, Kotsou S (2001) The blood leukocyte count and its prognostic significance in severe head injury. Surg Neurol 55: 190-196

20. Lustenberger T, Inaba K, Barmparas G (2011) Ethanol intoxication is associated with a lower incidence of admission coagulopathy in severe traumatic brain injury patients. J Neurotrauma 28:16991706
21. Morán GE, Tamariz BA, Ruiz CJI et al (2018) Correlation of leukocytosis and intracranial injury in patients with traumatic brain injury. Rev Asoc Mex Med Crit y Ter Int 32(4):208-216

22. Shi J, Dong B, Mao Y et al 2016) Review: Traumatic brain injury and hyperglycemia, a potentially modifiable risk factor. Oncotarget 7:71052-771061

23. Tang J, Zhou LM, Jiang H et al (2012) The roles and administration methods of insulin in the early treatment of acute brain injury. Zhongguo Yishi Zazhi 14:1472-1474

24. Paiva W, Bezerra D, Amorim R, Figueiredo EG, Tavares WM, de Andrade AF, Teixeira MJ (2011) Serum sodium disorders in patients with traumatic brain injury. Ther Clin Risk Manag 7:345-349

25. Mayr R, Troyer S, Kastenberger T, Krappinger D, Rosenberger R, Obwegeser A, el Attal R (2012) The impact of coagulopathy on the outcome of traumatic epidural hematoma. Arch Orthop Trauma Surg 132:1445-1450

26. Wafaisade A, Lefering R, Tjardes $\mathrm{T}$ et al (2010) Acute coagulopathy in isolated blunt traumatic brain injury. Neurocrit Care 12:211219

27. Walcott BP, Khanna A, Kwon C-S, Phillips HW, Nahed BV, Coumans JV (2014) Time interval to surgery and outcomes following the surgical treatment of acute traumatic subdural hematoma. J Clin Neurosci 21(12):2107-21011

28. Gurer B, Kertmen H, Yilmaz ER, Dolgun H, Hasturk AE, Sekerci Z (2017) The surgical outcome of traumatic extraaxial hematomas causing brain herniation. Turk Neurosurg 27(1):37-52

29. Matsushima K, Inaba K, Siboni S et al. (2015) Emergent operation for isolated severe traumatic brain injury: does time matter? J Trauma Acute Care Surg 79: 838-842

30. Rush B, Rousseau J, Sekhon MS, Griesdale DE (2016) Craniotomy versus craniectomy for acute traumatic subdural hematoma in the United States: a national retrospective cohort analysis. World Neurosurg 88:25-31

Publisher's Note Springer Nature remains neutral with regard to jurisdictional claims in published maps and institutional affiliations. 